\title{
Florida's Large Carnivores ${ }^{1}$
}

\author{
Martin B. Main, Ginger Allen, and Melvin E. Sunquist ${ }^{2}$
}

\section{Introduction}

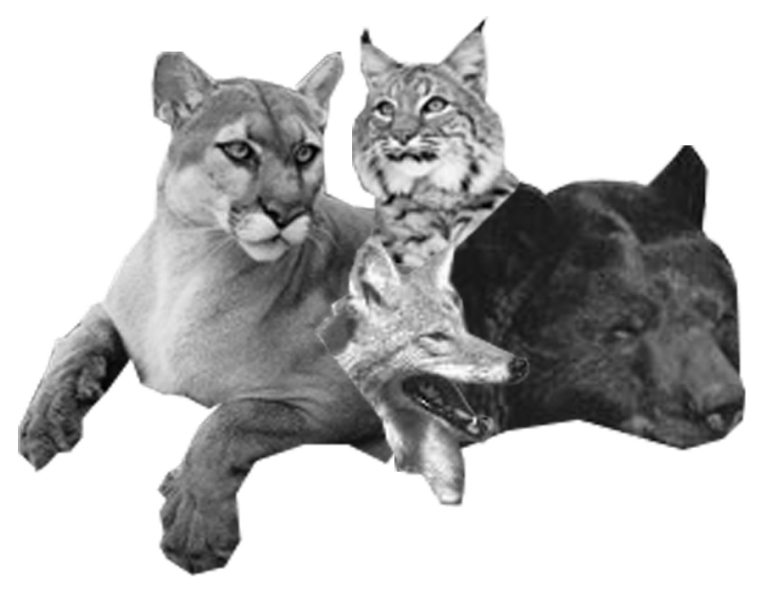

Figure 1. Clockwise from left: Florida Panther, bobcat, Florida Black Bear, coyote.

Florida's diverse wildlife includes a number of large, predatory mammals known as carnivores. Carnivores are mammalian predators of the Order Carnivora, and among other things are characterized by having teeth designed for tearing and consuming flesh. However, some carnivores, such as bears and coyotes, are omnivorous and eat both animal and plant material. This document provides an overview of Floridas four largest carnivores: the Florida panther, black bear, bobcat, and the coyote.

Although ecologists and wildlife enthusiasts may consider the existence of Florida's carnivores both important and fortunate in a world where large carnivores are rapidly disappearing, attitudes have not always been kind toward large predatory animals. When European settlers first arrived on North American shores, they brought with them a prejudice against predators, and the first wildlife legislation enacted in the British colonies was a wolf bounty. This prejudice dominated wildlife policy until conservationist Aldo Leopold demonstrated the important role of predator-prey relationships in the 1950s, when he documented the rise and eventual collapse of a deer population following predator removal. Predation, and particularly predation by top-level carnivores, is a necessary component of healthy ecosystems, and numerous studies have demonstrated that the loss of top-level predators may lead to a decline in biodiversity.

Predator-prey relationships are complex. For example, the removal of large predators may lead to an increase in deer and other herbivore populations that may damage habitat and reduce carrying capacity for these species. Elimination of large predators may

1. This document is Fact Sheet WEC 183, one of a series of the Department of Wildlife Ecology \& Conservation, Florida Cooperative Extension Service, Institute of Food and Agricultural Sciences, University of Florida. Publication date: June 2004. Please visit the Edis Web site at http://edis.ifas.ufl.edu

2. Martin B. Main, associate professor and wildlife extension specialist; Ginger M. Allen, senior biologist; and Melvin E. Sunquist, associate professor, Department of Wildlife Ecology and Conservation, Institute of Food and Agricultural Sciences. University of Florida, Gainesville FL $32611-0430$.

The Institute of Food and Agricultural Sciences (IFAS) is an Equal Employment Opportunity - Affirmative Action Employer authorized to provide research, educational information and other services only to individuals and institutions that function without regard to race, creed, color, religion, age, disability, sex, sexual orientation, marital status, national origin, political opinions or affiliations. For information on obtaining other extension publications, contact your county Cooperative Extension Service office. Florida Cooperative Extension Service / Institute of Food and Agricultural Sciences / University of Florida / Larry R. Arrington, Interim Dean 
result in an increase in smaller, middle-sized predators. An increase in middle-sized predators (mesopredators) may increase predation pressure on small game and nongame species. Consequently, as our understanding of the complex interplay between predators and prey has increased, so has our acknowledgment that these relationships should be maintained.

\section{Florida Panther (Puma concolor coryi)}

First described in 1896 by naturalist and hunter Charles Barney Cory, the Florida panther is one of 15 subspecies of puma that occur in North America. Also known as cougars and mountain lions, puma are one of the most widely distributed carnivores in the Americas, ranging from southern South America into northern North America. However, only the Florida panther, which is smaller, has longer legs, smaller feet, and a shorter, darker coat than western species of puma, occurs in the southeastern United States. Historically, the Florida panther ranged throughout much of the southeast. Today, however, the only remaining breeding population is restricted to extreme southwest Florida, where large tracts of natural areas still exist on public conservation areas and privately owned cattle ranches and agricultural lands. Because of the decline in numbers, the highly restricted breeding population, and the large area requirements for each individual (Table 1), the Florida panther is in danger of extinction and is listed as an endangered species at both the federal and state levels. Despite conservation efforts, continued habitat loss and fragmentation associated with development and road construction threatens the continued survival of this large cat.

To survive, panthers require suitable habitat, prey, and space. Panthers are territorial, which means they defend a home range against unrelated panthers, and confrontations between panthers may end in injury or death. Like all cats, the Florida panther is strictly a flesh-eating carnivore, so large areas are needed to meet their energy requirements. Depending on the quality of the habitat, the home range of an adult male panther may be as much as 200 square miles and overlap the home ranges of several females with which he mates and which have smaller home ranges of about 75 square miles. Because panthers use such large areas, they utilize many different habitats but prefer mature upland forests such as hardwood hammocks and pinelands, where they hunt for their preferred prey, white-tailed deer and feral hogs.

\section{Bobcat (Lynx rufus floridanus)}

Florida's other native wild cat is the bobcat. Like the panther, the Florida bobcat is a distinct subspecies, of which there are 12 in North America. Also like the panther, bobcats are entirely carnivorous, preying upon small animals such as rabbits, rodents, and birds and much less frequently on large animals such as white-tailed deer. Weighing 15-35 pounds, bobcats are much smaller than panthers (Table 1). Bobcats also have much shorter tails that possess a white tip and various other markings that make them easy to distinguish from panthers. For more information on visual comparisons between bobcats and panthers, refer to the University of Florida EDIS document "Did I see a Panther?" (online: http://edis.ifas.ufl.edu/UW144).

Bobcats are territorial, but because they are smaller and hunt prey that is more abundant, they require less land area than do larger carnivores. Home ranges vary from 5-15 square miles, with male home ranges being larger and overlapping with home ranges of several females. Bobcats are found throughout Florida and use a variety of habitats. Bobcat populations are not listed at the state or federal level as threatened or endangered.

\section{Florida Black Bear (Ursus americanus Floridanus)}

The Florida Black Bear is one of 16 subspecies of black bear that occur in North America. Although not much different looking than black bears in other parts of North America, the Florida Black Bear does have some morphological differences, such as a highly arched forehead and long, narrow skull. Breeding populations of the Florida Black Bear occur in several areas of the state, but because these populations are isolated and threatened by continued habitat loss, the Florida Black Bear is listed as a threatened species in Florida (Table 1). 
The Florida Black Bear has an omnivorous (plant and animal) diet and can utilize a wide range of food items and habitats in which to find them. Although bears are often predatory when opportunity allows, diet studies typically report that fruit and other plant material constitute the highest percentages of items in the diet of Florida Black Bears. Because diet requirements that include plants are more easily met, black bear home ranges are smaller than those used by panthers, averaging about 110 square miles for adult males and 20 square miles for adult females. Unlike panthers and bobcats, black bears are not territorial, but instead have a spatial arrangement based on a dominance hierarchy. Home range overlap is common, but bears are solitary and avoid encounters with more dominant individuals.

\section{Coyote (Canis latrans)}

The coyote is a relatively recent addition to Florida's list of large carnivores. Following the elimination of wolves throughout most of the continental United States during the last century, coyotes expanded across the country into eastern states. Coyotes were documented in the Florida Panhandle during the 1970s and expanded their range into south Florida by the 1990s (for additional information, see "Coyotes Expand Their Range Into South Florida," online: http://edis.ifas.ufl.edu/UW146). Although 16 subspecies of coyotes are documented in North America, it is not clear which subspecies have contributed to Florida populations. Because coyotes arrived in Florida primarily by way of range expansion (although intentional introductions of small numbers by hunters have been documented), they technically are not an exotic species, nor are they historically native to Florida. In many ways, they are a species without status.

Historically, red wolves were Florida's largest canine predator, but red wolves were extirpated from Florida during the early-mid 1900s. Coyotes are smaller than wolves and larger than foxes. Averaging $30-40$ pounds, coyotes are also smaller than many feral dogs. However, unlike feral dogs, coyotes are skilled hunters and truly wild animals. Although coyotes prefer open, upland habitats such as rangeland, they can use a diversity of habitats and are opportunistic in their diets. Coyotes primarily prey upon small mammals such as rabbits and rodents, but also prey upon large mammals such as white-tailed deer, particularly fawns. Coyotes also consume insects and large amounts of fruit at certain times of the year. Coyotes are scavengers and will eat carrion and sometimes kill livestock. Like other carnivores, coyotes are territorial and establish home ranges that typically range from 5-20 square miles. These ranges are occupied by a breeding male and female, which is the basic social unit in coyotes. Although much is not known about coyotes in Florida, it seems clear that coyotes are here to stay.

\section{Interactions Among Florida's Large Carnivores}

Differences in behavioral patterns, habitat preferences, and diets partition resources and reduce competition among Florida's large carnivores. Consequently, each of Florida's large carnivores fulfills distinct ecological roles.

The Florida panther is principally a predator of the forest and a stalker of large prey, such as deer and feral hogs. Panthers will also consume smaller prey, such as rabbits and armadillos, but these are not their preferred diet. Bobcats are also stalking predators of the forest, but occupy many other habitats as well. The diet of bobcats is principally composed of small mammals and birds, although bobcats will occasionally kill large prey such as deer, especially fawns. Bears occupy a variety of habitats and primarily eat plant material, but will scavenge carrion and kill animals of all sizes if the opportunity presents itself. Coyotes are primarily predators of small animals, like the bobcat, but will also kill large prey, scavenge, and eat plant material. Of all the carnivores, the coyote diet is the most diverse and has the greatest potential for competition with other species. However, habitats preferred by coyotes are typically more open than those of panthers or bears. Coyotes also use different hunting strategies than panthers or bobcats. Coyotes are coursing predators, which means they employ a hunting strategy where they range over large areas in efforts to encounter and flush prey, as opposed to stalking prey. Dietary and 
behavioral differences, as well as research conducted in Florida and other states, indicate that coyotes, bobcats, bears, and panthers partition resources in ways that enable these species to coexist.

\section{Conservation and Management}

Among Florida's large carnivores, the Florida panther is the most imperiled. The number of panthers currently existing in southwest Florida is estimated at less than 100, and prospects are not promising that the panther population will increase substantially. In fact, continued urbanization of southwest Florida, including the construction of new and larger roads to support this growth, continues to constrict and confine the panther population into ever smaller areas. Because many panthers are radio-collared, they can be tracked and sources of mortality can be determined. Vehicle collisions with panthers constitute about half of all documented sources of death. Natural causes, particularly fights between panthers, constitute the other principal source of mortality. Panther deaths have also been attributed to feline leukemia, which is believed to be transmitted to panthers by free-ranging and feral housecats. The future of the Florida panther is dependent upon conservation action ensuring that enough space and suitable wildlife corridors between natural areas are preserved to enable these large cats to continue to survive in Florida.

The future of the Florida Black bear is also in jeopardy. Listed as a Florida threatened species, the Florida population of black bears is estimated at 1,000-1,500 individuals. As with the panther, vehicle collisions are the major source of mortality for bears. Illegal hunting is also a concern in some areas. An increasingly serious problem is that of nuisance bears, which are attracted to garbage and other sources of food provided by humans who build homes in bear habitat. Unfortunately, relocation of nuisance bears is expensive, typically not effective, and unpopular because nuisance bears must sometimes be destroyed. Continued loss and fragmentation of habitat due to residential development, road construction, and conversion of land to other uses divides and isolates black bear populations and is the principal threat to the future of the black bear in Florida.
Both bobcats and coyotes are widely distributed throughout Florida, and populations of both species appear healthy. Bobcats and coyotes both are able to survive in natural and agricultural landscapes. Although bobcats are likely more sensitive to urbanizing landscapes, both bobcats and coyotes have been observed in residential areas, parks, and other urban green space. The smaller size and, in the case of the coyote, an ability to adapt to highly diverse living conditions make these two species better able to survive in Florida's rapidly changing landscapes than panthers or bears. In addition to the typical sources of mortality (roads, disease, conflict), both bobcats and coyotes are hunted in Florida, and coyotes are sometimes targeted for control to protect livestock.

Conservation of Florida's large carnivores is important for maintaining the complex ecological relationships that exist among predators and prey and herbivores and plant communities. Loss of top-level predators in ecosystems can have unpredictable results. Moreover, by conserving the large tracts of habitat required by carnivores, we ensure that sufficient habitat is preserved to support the many other species of plants and animals that constitute Florida's natural environment.

\section{References \& Additional Information}

Brown, Larry N. 1997. Mammals of Florida. Miami, Florida: Windward Publishing, Inc. pp224.

Bunnell, F.L. and D.E.N. Tait. 1981. Population dynamics of bears-implications. Pp 75-98. In S.R. Humprey, Ed., Rare and Endangered Biota of Florida, Vol 1. Mammals:265-273.

Coates, S.F., M.B. Main, J.J. Mullahey, J.M. Schaefer, G.W. Tanner, M.E. Sunquist, and M.D. Fanning. 1998. The coyote (Canis Latrans): Florida's newest predator. University of Florida Cooperative Extension Service Fact Sheet WEC 124. 7 pp. University of Florida, UF/IFAS EDIS Database, http://edis.ifas.ufl.edu/UW127.

Kautz, Randy. 1994. Historical Trends within the Range of the Florida Panther. In Dennis Jordan, Ed., Proceedings of the Florida Panther Conference. U.S. Fish and Wildlife Service. 
Land, Darrell. 1994a. Florida Panther Population Dynamics in Southwest Florida. In Dennis Jordan, Ed., Proceedings of the Florida Panther Conference. U.S. Fish and Wildlife Service.

Land, Darrell. 1994b. Panther Use of the Southern Florida Landscape. In Dennis Jordan, Ed., Proceedings of the Florida Panther Conference. U.S. Fish and Wildlife Service.

Maehr, David S. 1997. The Florida Panther: Life and Death of a Vanishing Carnivore. Washington, D.C.: Island Press.

Main, M.B. 2001. Monitoring coyote populations in Florida: Annual Update of the Statewide Scent Station Survey 1997-2000. University of Florida Cooperative Extension Service Fact Sheet WEC 149. 6 pp. University of Florida, UF/IFAS EDIS Database, http://edis.ifas.ufl.edu/UW145, http://edis.ifas.ufl.edu/UW127.

Main, M.B. 2002. Visual Guide to Interpreting Physical Evidence of Coyote Predation on Domestic Livestock. University of Florida Cooperative Extension Service Fact Sheet WEC 158. Poster. University of Florida, UF/IFAS Extension Digital Information Source (EDIS) Database, http://edis.ifas.ufl.edu/UW171, http://edis.ifas.ufl.edu/UW127.

Main, M.B., Coates, S.F., and G.M. Allen. 2001. Coyotes Expand Their Range into South Florida. University of Florida Cooperative Extension Service Fact Sheet WEC 150. 5 pp. University of Florida, UF/IFAS Extension Digital Information Source (EDIS) Database, http://edis.ifas.ufl.edu/UW146, http://edis.ifas.ufl.edu/UW127.

Schortemeyer, J.L. 1994. Habitat Management for Panthers in South Florida. In Dennis Jordan, Ed., Proceedings of the Florida Panther Conference. U.S. Fish and Wildlife Service.

Sunquist, M., and F. Sunquist. 2002. Wild Cats of the World. Chicago: University of Chicago Press.

Whitaker, J.O. Jr. and W.J. Hamilton Jr. 1998. Mammals of the Eastern United States. London: Cornell University. pages. 393-497.
Wooding, J.B., and J.R. Brady. 1987. Black bear roadkills in Florida. Proc. Annual Conf. Southeast Assoc. Fish and Wildl. Agencies 41:438-442. 


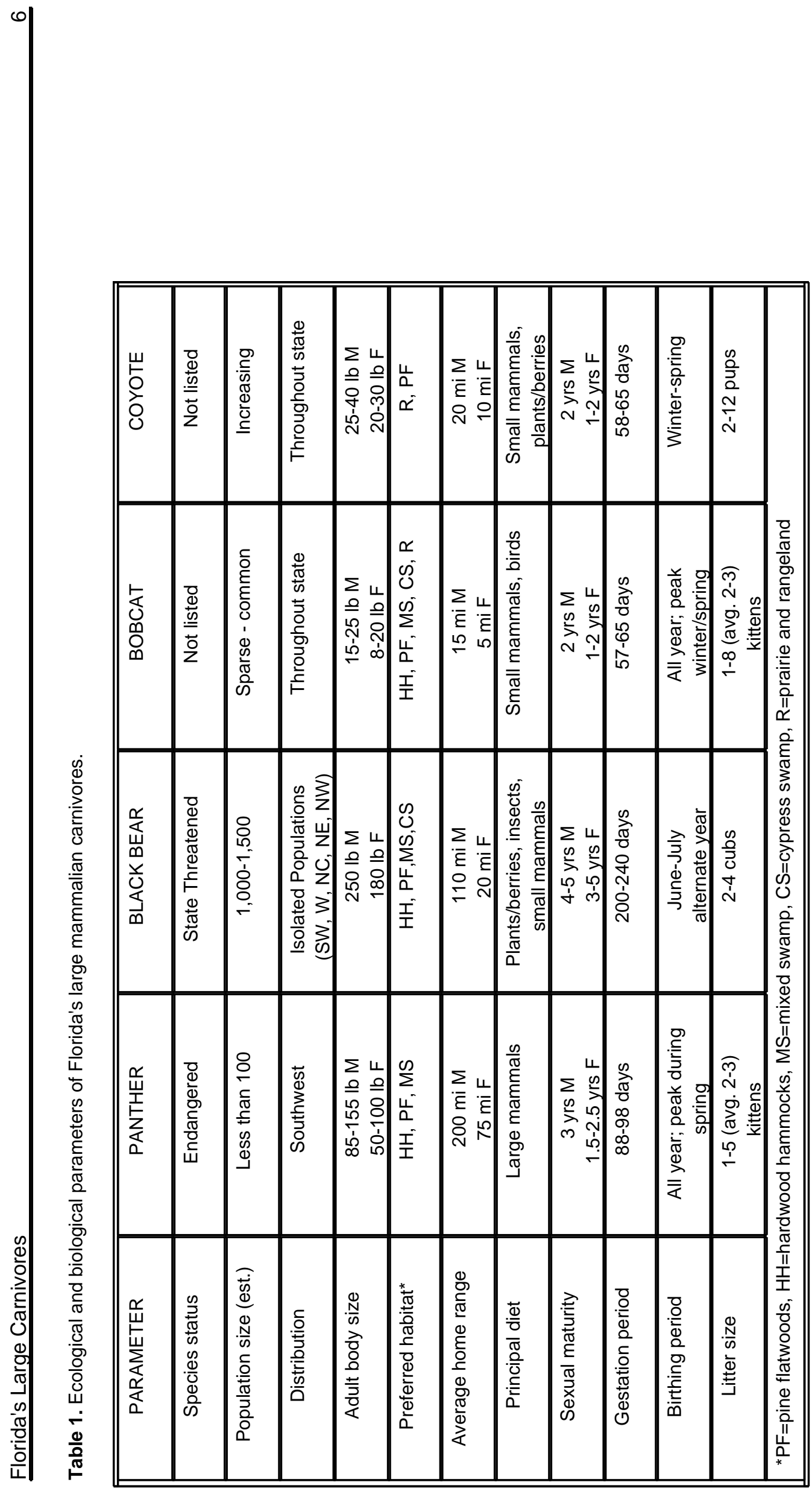

